\title{
Desempenho animal em pasto de aveia e azevém com distintas biomassas de lâminas foliares
}

\author{
Duilio Guerra Bandinelli(1), Fernando Luiz Ferreira de Quadros ${ }^{(1)}$, Adriano Rudi Maixner(1), \\ Luiz Felipe Cattani Simões ${ }^{(1)}$, Carlos Eduardo Nogueira Martins ${ }^{(1)}$, Alexandre Coradini Fontoura da Silva ${ }^{(1)}$, \\ Naíme de Barcellos Trevisan ${ }^{(1)}$, Marcos da Silva Brum ${ }^{(1)}$ e Niumar Dutra Aurélio(1)
}

(1)Universidade Federal de Santa Maria, Dep. de Zootecnia, CEP 97105-900 Santa Maria, RS. E-mail: bandlli@zipmail.com.br, fquadros@ccr.ufsm.br, armaixner@yahoo.com.br, Ifcsimoes@bol.com.br, cenmartins@ig.com.br, salso@vant.com.br, naime.trevisan@zipmail.com.br, marcossbrum@yahoo.com.br, niumar@mail.ufsm.br

Resumo - O objetivo deste trabalho foi avaliar o efeito de biomassas de lâminas foliares no desempenho animal. Utilizou-se mistura de aveia (Avena strigosa Schreb) e azevém (Lolium multiflorum Lam.), para determinar quantidades adequadas de sua biomassa no manejo da pastagem. Foram realizados dois experimentos, na estação fria de 2002 e 2003. Na avaliação de 2002, os valores de biomassa de lâminas foliares foram de $360 \mathrm{~kg} \mathrm{ha}^{-1}$ (baixa) e $630 \mathrm{~kg} \mathrm{ha}^{-1}$ (alta). Em 2003, foram obtidas biomassas de 352, 422 e $507 \mathrm{~kg} \mathrm{ha}^{-1}$, classificadas como baixa, média e alta, respectivamente. O método de pastejo foi contínuo, com taxa de lotação variada; os animais utilizados foram terneiros da raça Charolês e cruzados com Nelore, com idade inicial de nove meses. As variáveis de produção animal avaliadas, nos dois anos, foram: ganho médio diário, carga animal e ganho de peso vivo por área. As distintas biomassas de lâminas foliares mantidas não são fatores limitantes ao desempenho animal.

Termos para indexação: Avena strigosa, Lolium multiflorum, oferta de forragem, taxa de lotação.

\section{Animal performance in oat and Italian ryegrass pastures under leaf lamina biomass levels}

\begin{abstract}
The objective of this work was to evaluate the effect of different leaf lamina biomass over animal performance. A mixture of oat (Avena strigosa Schreb) and Italian ryegrass (Lolium multiflorum Lam.) was used to determine adequate levels of leaf lamina biomass for pasture management. Two trials were made, in 2002 and 2003 cool seasons. In 2002 evaluation, leaf lamina biomass values were of $360 \mathrm{~kg} \mathrm{ha}^{-1}$ (low) and $630 \mathrm{~kg} \mathrm{ha}^{-1}$ (high). In 2003, values obtained for leaf lamina biomasses were of 352, 422 and $507 \mathrm{~kg} \mathrm{ha}^{-1}$, being classified as low, medium and high, respectively. Grazing method was continuous, with variable stocking rate; testing animals were calves of Charolais breed and its crosses with Nelore breed, with initial age of nine months. Evaluated variables in animal production, in both years, were: average daily gain, stocking rate and live weight gain per area. Leaf lamina biomasses evaluated are not limiting factors to animal performance.
\end{abstract}

Index terms: Avena strigosa, Lolium multiflorum, forage offer, stocking rate.

\section{Introdução}

A produção animal em pastagens de estação fria é dependente da relação entre o comportamento animal e os atributos das pastagens, dentre os quais, a densidade de folhas é o fator determinante de consumo, pois os herbívoros selecionam a forragem conforme a distribuição de folhas verdes, dentro dos horizontes de pastejo. Huillier et al. (1986) afirmaram que avanços em produção animal serão obtidos, mantendo-se pastagens com folhas verdes acessíveis nos horizontes superficiais.

A relação entre o produto animal e a abundância de forragem é geralmente expressa por uma função exponencial. Essa medida, em experimentos de pastejo, normalmente é contemplada por alguma variável independente, dentre as quais se destacam, como as mais utilizadas, a massa e oferta de forragem, e a altura da pastagem. O efeito dessas variáveis, sobre a produção, está associado à oportunidade de o animal colher maior ou menor quantidade de forragem, com qualidade superior ou inferior (Heringer \& Carvalho, 2002).

O manejo de pastagens consiste na tomada de decisões técnicas capazes de manter o equilíbrio entre os dois fatores conflitantes de produção: a exigência nutricional do animal sob pastejo, e a exigência fisiológica da planta forrageira, para alcançar e manter elevada 
produtividade (Corsi \& Nascimento Junior, 1994). Assim, o sistema de manejo adotado tem como objetivo conciliar a exigência do animal e da planta forrageira, para que possam ser atingidos resultados satisfatórios sem prejudicar nenhum dos componentes envolvidos na produção.

O objetivo deste trabalho foi avaliar o efeito de biomassas foliares, da mistura de aveia preta (Avena strigosa Schreb) e azevém (Lolium multiflorum Lam.), sobre o desempenho animal.

\section{Material e Métodos}

Os experimentos foram conduzidos na Universidade Federal de Santa Maria, RS, 294' $\mathrm{S}, 5^{\circ} 42^{\prime} \mathrm{W}$ e $95 \mathrm{~m}$ de altitude, nos anos de 2002 e 2003. O clima é subtropical úmido (Cfa) (Moreno, 1961), com temperatura média anual de $19^{\circ} \mathrm{C}$. O solo da área experimental é classificado como Argissolo Vermelho distrófico arênico (Embrapa, 1999). A análise química do solo, antes da instalação dos experimentos, revelou os seguintes valores médios em 2002: $\mathrm{pH}$ 4,1, MO, 3,4\%; $\mathrm{P}$, $11 \mathrm{mg} \mathrm{L}^{-1}$; K, 101,7 $\mathrm{mg} \mathrm{L}^{-1}$; bases, 22,8\%; alumínio, 48,3\%. Em 2003, os valores médios foram: $\mathrm{pH} 4,4$; MO, 2,5\%; P, 7,1 mg L-1 ${ }^{-1}$, 40,7 mg L-1; bases, 24,5\%; alumínio, 52,3\%.

Por ocasião da semeadura, em 2002, foram aplicados os herbicidas glifosato e 2,4-D, nas dosagens de 3 e $0,8 \mathrm{~L} \mathrm{ha}^{-1}$, respectivamente, para controle da vegetação, no dia 3/5/2002. Em 2003, utilizou-se apenas glifosato, $3 \mathrm{~L} \mathrm{ha}^{-1}$, no dia 7/5/2003. A área total semeada nos dois anos foi de cerca de seis hectares, dividida em seis pastos (repetições), com área total de 4,43 ha e uma área adicional de 1,5 ha, destinada à permanência de animais reguladores.

As espécies utilizadas foram aveia e azevém cultivar Comum. A semeadura direta da aveia $\left(80 \mathrm{~kg} \mathrm{ha}^{-1}\right)$, com $17 \mathrm{~cm}$ entre linhas, e a semeadura a lanço do azevém (40 $\mathrm{kg} \mathrm{ha}^{-1}$ ) foram realizadas nos dias 11/5/2002, 14 e 15/5/2003. Antes da realização do experimento, a área era manejada com a utilização da mistura aveia + azevém (estação fria) e milheto (Pennisetum americanum (L.) Leeke) (estação quente). Em 2002, a semeadura direta foi realizada sobre a palhada de milheto, e entre os anos de 2002 e 2003, a área ficou em pousio, com a semeadura direta sobre espécies de ocorrência espontânea.

A adubação de base aplicada foi de 200 e $250 \mathrm{~kg} \mathrm{ha}^{-1}$, da fórmula 5-20-20 (NPK) e, em cobertura, 98,5 e 119,3 kg ha-1 de N, divididos em duas aplicações em 2002
(45,7 kg ha ${ }^{-1}$ de $\mathrm{N}$ em 20/6; 52,8 kg ha-1 de N em 12/8), e dividida em três aplicações em 2003 (29,3 kg ha-1 de $\mathrm{N}$ em 24/6; $45 \mathrm{~kg} \mathrm{ha}^{-1}$ de $\mathrm{N}$ em 31/7 e $45 \mathrm{~kg} \mathrm{ha}^{-1}$ de N em 26/8), tendo sido utilizada uréia como fonte de $\mathrm{N}$.

Os tratamentos pretendidos, quanto à biomassa de forragem ( $\mathrm{kg} \mathrm{ha}^{-1}$ de MS) de lâminas foliares (BLF), foram de 300, 600 e $900 \mathrm{~kg} \mathrm{ha}^{-1}$ de BLF em 2002. Em virtude da baixa densidade de plantas, observada em campo, os tratamentos precisaram ser alterados, tendo passado 360 (baixa) a $630 \mathrm{~kg} \mathrm{ha}^{-1}$ de BLF (alta). Foram utilizadas quatro repetições para o tratamento de alta e duas repetições para baixa BLF.

Em 2003, em razão dos resultados de produção animal, obtidos na baixa BLF do ano anterior, optou-se pela manutenção de índices médios que pudessem ser limitantes à produção animal (350 e $420 \mathrm{~kg} \mathrm{ha}^{-1} \mathrm{de} \mathrm{BLF}$ ) e ter um nível próximo à alta BLF de 2002 (500 kg ha-1 de BLF), para assim indicar limites de BLF a serem manejados. Nesse ano (2003), foram utilizadas duas repetições por tratamento.

Nos dois anos, o método de pastejo foi contínuo, com taxa de lotação variável, tendo-se utilizado a técnica de animais reguladores (Mott \& Lucas, 1952). Foram avaliados terneiros inteiros, com idade inicial de nove meses e peso médio de 174,8 kg (2002) e 179,3 kg (2003), da raça Charolês e suas cruzas com Nelore. A carga animal ( $\mathrm{kg} \mathrm{ha}^{-1}$ de peso vivo) foi ajustada, conforme a necessidade, a cada 15 dias, aproximadamente, com o objetivo de manter as BLF pretendidas.

As estimativas de biomassa de forragem ( $\mathrm{BF}=$ lâmina foliar verde + colmo + bainha) e de BLF (lâmina foliar verde) foram realizadas a cada 14 dias, pelo método de estimativa visual, com dupla amostragem (Mannetje, 2000). Foi realizada, em cada repetição, a estimativa visual da BF média e da porcentagem de lâminas foliares na amostra, tendo sido estimadas no mínimo 20 amostras de $0,25 \mathrm{~m}^{2}$ de área, das quais em cinco o material foi cortado rente ao solo.

A partir das amostras de forragem cortadas, foram determinados os componentes lâmina foliar verde, colmo + bainha e material senescente (excluído da BF), por meio de separação manual. O material foi secado em estufa de ar forçado, até atingir peso constante e, posteriormente, pesado. Com os valores de massa seca (MS) dos componentes, foi realizada uma regressão entre o valor estimado e o cortado (porcentagem de lâminas foliares e BF das respectivas amostras cortadas). Os valores estimados foram incluídos nas equações de regressão e, desta forma, foram obtidas as BF e BLF ( $\left.\mathrm{kg} \mathrm{ha}^{-1}\right)$ médias, para cada repetição, na avaliação. 
O período de pastejo de 2002 foi de 12 de julho a 23 de outubro. Os animais foram mantidos em pastagem nativa e receberam suplementação de silagem de sorgo no período que antecedeu ao experimento. O critério utilizado para entrada dos animais na pastagem, em 2003, foi o início do acamamento da aveia. Os animais entraram todos juntos no experimento (2002 e 2003), tendo apenas as cargas iniciais sido diferenciadas, em função de tratamento. Os períodos de avaliação da produção animal foram de 12/7 a 15/8, 16/8 a 14/9 e 15/9 a 23/10 de 2002. As pesagens individuais dos animais testes e reguladores foram realizadas no início e final de cada período de pastejo, após jejum de sólidos e líquidos de 18 horas (2002) e seis horas (2003).

Em 2003, o período de pastejo foi de 17/7 a 10/10. Os animais foram submetidos a um período de cinco dias de adaptação à pastagem, mantidos em campo nativo e receberam suplementação de silagem de sorgo, com pastejo horário (duas a quatro horas) em pastagem de aveia + azevém. Em 2003, o critério de entrada dos animais baseou-se na BLF das repetições de alta BLF. Os períodos de avaliação da produção animal foram de 17/7 a 14/8, 15/8 a 12/9 e 13/9 a 10/10 de 2003.

Em ambos os anos, foram utilizados três animais testes por repetição e um número variável de animais reguladores. Os animais possuíam livre acesso à água nas unidades experimentais. O controle de endoparasitas e ectoparasitas foi realizado com dosificações aos animais de Doramectina (1 mL por $50 \mathrm{~kg}$ de peso vivo - PV).

$\mathrm{O}$ ganho de peso médio diário (GMD), expresso em $\mathrm{kg}$ por animal, foi determinado pela diferença entre peso final e inicial dos animais testes, em cada período experimental, dividido pelo número de dias do período. A carga animal (CA) por período, expressa em $\mathrm{kg} \mathrm{ha}^{-1}$ de PV foi obtida pela soma do peso médio dos animais testes e reguladores, multiplicado pelo número de dias em que esses permaneceram na repetição, dividido pelo número de dias do período de pastejo.

$\mathrm{O}$ ganho de peso vivo por hectare (GPV ha-1), expresso em $\mathrm{kg} \mathrm{ha}^{-1}$ de PV, foi obtido pelo somatório do ganho de peso dos animais testes. A esse valor foi adicionado o produto entre o GMD da repetição e o número de animais reguladores, e de dias em que estes permaneceram na repetição, nos respectivos períodos. O GPV total foi calculado pelo somatório dos GPV dos períodos de utilização.

Nas avaliações da taxa de acúmulo de BF e BLF, com intervalo de aproximadamente 28 dias, foram utilizadas três gaiolas de exclusão de pastejo por repetição. A produção total de BF foi determinada pelo somatório das produções de matéria seca, de cada período, acrescido da BF média do início do período de utilização da pastagem.

A oferta real de BF e BLF (kg de MS por $100 \mathrm{~kg}$ de $\mathrm{PV})$, média por período, foi determinada pela fórmula: 100[(BF ou BLF + (taxa de acúmulo $\mathrm{x}$ número de dias do período))/número de dias do período]/CA].

$\mathrm{O}$ delineamento experimental foi o inteiramente casualizado, com número variável de repetições. Para comparar os efeitos dos tratamentos, foi utilizado um modelo de análise de variância por testes de aleatorização e ordenação do programa MULTIV (Pillar, 1997).

\section{Resultados e Discussão}

Na média dos tratamentos, a BF e a BLF foram $91,6 \%$ e $76,2 \%$ superiores no tratamento de alta BLF, e em ambas as variáveis houve diferença entre os tratamentos, no decorrer dos períodos avaliados (Tabela 1). Os valores de BF do tratamento de alta BLF, conforme Mott (1984), poderiam propiciar o máximo desempenho animal para a mistura avaliada, pois são próximas às massas de forragem (MF), entre 1.200 e $1.600 \mathrm{~kg} \mathrm{ha}^{-1}$ de MS, sugeridas pelo autor. Segundo Moraes (1991), quando a MF estiver abaixo desses valores, o consumo pode ser reduzido, com a conseqüente diminuição no desempenho animal.

A BF média do tratamento de baixa BLF (648 kg ha-1 de MS) foi próxima a 50\% do considerado limitante. Entretanto, os valores de GMD (Tabela 2), obtidos na baixa BLF foram semelhantes aos obtidos com a MF preconizada, mantida na alta BLF. Apenas no período de 16/8 a 14/9 de 2002, foram observadas diferenças entre os tratamentos no GMD.

Tabela 1. Biomassas de forragem e de lâminas foliares (BLF), da pastagem de aveia (Avena strigosa) e azevém (Lolium multiflorum), em 2002(1).

\begin{tabular}{lrrrrr}
\hline BLF & \multicolumn{3}{c}{ Período de avaliação } & Média & CV \\
\cline { 2 - 4 } & $12 / 7 \mathrm{a} 15 / 8$ & $16 / 8$ a 14/9 & $15 / 9$ a 23/10 & & $(\%)$ \\
\hline \multirow{5}{*}{ Baixa } & $786,0 \mathrm{~b}$ & $622,0 \mathrm{~b}$ & $536,0 \mathrm{~b}$ & $648 \mathrm{~b}$ \\
Alta & $1.199,3 \mathrm{a}$ & $1.330,3 \mathrm{a}$ & $1.196,3 \mathrm{a}$ & $1.242 \mathrm{a}$ \\
\hline Média & $1.061,5 \mathrm{~A}$ & $1.094,2 \mathrm{~A}$ & $976,2 \mathrm{~B}$ & & 6,86 \\
\hline \multicolumn{5}{c}{ Biomassa de lâminas foliares $\left(\mathrm{kg} \mathrm{ha}^{-1}\right.$} & de MS) \\
Baixa & $440,5 \mathrm{~b}$ & $402,5 \mathrm{~b}$ & $238,0 \mathrm{~b}$ & $360,3 \mathrm{~b}$ \\
Alta & $639,3 \mathrm{a}$ & $731,5 \mathrm{a}$ & $537,0 \mathrm{a}$ & $635,9 \mathrm{a}$ \\
\hline Média & $573,0 \mathrm{~B}$ & $621,8 \mathrm{~A}$ & $437,3 \mathrm{C}$ & \multicolumn{3}{c}{6,93} \\
\hline
\end{tabular}

(1)Médias seguidas de letras distintas, minúsculas nas colunas e maiúsculas nas linhas, diferem entre si $(\mathrm{p} \leq 0,064)$ pelo teste de aleatorização. 
Canto et al. (1997), ao trabalhar com aveia preta adubada com $100 \mathrm{~kg} \mathrm{ha}^{-1}$ de $\mathrm{N}$, ou em mistura de ervilhaca (Vicia sativa L.) + azevém, utilizaram novilhos de 20 meses de idade, com PV inicial de 320 kg, e observaram MF médias de 845 e 790,7 kg ha-1 de MS, e GMD de 1,41 e 1,21 kg por animal, respectivamente, tendo demonstrado que, em pastagens de estação fria, o índice limitante de BF para o desempenho animal deve ser revisto.

Os GMD observados em 2002 foram superiores ou próximos aos verificados por outros autores, no mesmo período, com MF médias (aveia + azevém) superiores às observadas no presente estudo. Restle et al. (1999) observaram, em novilhos de sobreano, GMD de 0,968 kg por animal, com MF média próxima de $2.000 \mathrm{~kg} \mathrm{ha}^{-1} \mathrm{de}$ MS. Restle et al. (2000) observaram, ainda, em terneiras, um GMD de 0,836 kg por animal, na média dos tratamentos de fontes de $\mathrm{N}$, com MF média de $1.973 \mathrm{~kg} \mathrm{ha}^{-1}$ de MS. Roso \& Restle (2000) observaram em terneiras, um GMD de 0,738 a 0,706 kg por animal, e MF média de 1.821, 1.574 e $1.606 \mathrm{~kg} \mathrm{ha}^{-1}$ de MS, respectivamente, para as datas 10/9, 8/10 e 5/11. Pilau et al. (2004) observaram, em novilhas, GMD de 0,716 kg por animal, BF média de 1.033,3 $\mathrm{kg} \mathrm{ha}^{-1} \mathrm{de}$ MS

Tabela 2. Ganho médio diário, carga animal e ganho de peso vivo (PV) por área, e ofertas reais de biomassas, em pastagem de aveia (Avena strigosa) e azevém (Lolium multiflorum), em $2002^{(1)}$.

\begin{tabular}{|c|c|c|c|c|c|}
\hline \multirow{2}{*}{$\begin{array}{l}\text { Quantidade } \\
\text { de BLF }\end{array}$} & \multicolumn{3}{|c|}{ Período de avaliação } & \multirow{2}{*}{\multicolumn{2}{|c|}{ Média }} \\
\hline & $12 / 7$ a $15 / 8$ & $16 / 8$ a $14 / 9$ & $15 / 9$ a $23 / 10$ & & \\
\hline & \multicolumn{5}{|c|}{ Ganho médio diário ( $\mathrm{kg}$ por animal por dia) } \\
\hline Baixa & 0,423 & $1,072 b$ & 0,995 & 0,830 & \\
\hline Alta & 0,401 & $1,497 \mathrm{a}$ & 1,083 & 0,993 & \\
\hline \multirow[t]{2}{*}{ Média } & $0,408 \mathrm{~B}$ & $1,355 \mathrm{~A}$ & $1,053 \mathrm{~A}$ & & 21,4 \\
\hline & \multicolumn{5}{|c|}{ Carga animal (kg ha ${ }^{-1}$ de PV) } \\
\hline Baixa & $1.301,8 \mathrm{a}$ & $1.076,9$ & 969,6 & $1.116,1$ & \\
\hline Alta & $957,6 \mathrm{~b}$ & 956,2 & $1.086,9$ & $1.000,2$ & \\
\hline \multirow[t]{2}{*}{ Média } & $1.072,4$ & 996,4 & $1.047,8$ & & 17,1 \\
\hline & \multicolumn{5}{|c|}{ Oferta real de biomassa ( $\mathrm{kg}$ por $100 \mathrm{~kg}$ de PV) } \\
\hline Baixa & 5,33 & 7,16 & 3,15 & $5,21 b$ & \\
\hline Alta & 8,38 & 9,14 & 4,28 & $7,27 \mathrm{a}$ & \\
\hline \multirow[t]{2}{*}{ Média } & $7,36 \mathrm{~A}$ & $8,47 \mathrm{~A}$ & $3,90 \mathrm{~B}$ & & 25,6 \\
\hline & \multicolumn{5}{|c|}{ Oferta real de biomassa de lâmina foliar (kg por $100 \mathrm{~kg}$ de PV) } \\
\hline Baixa & 2,33 & 4,58 & 0,08 & 2,33 & \\
\hline Alta & 3,65 & 4,85 & 0,31 & 2,94 & \\
\hline \multirow[t]{2}{*}{ Média } & $3,21 \mathrm{~B}$ & $4,76 \mathrm{~A}$ & $0,23 \mathrm{C}$ & & 35,4 \\
\hline & \multicolumn{3}{|c|}{ Ganho de PV por área $\left(\mathrm{kg} \mathrm{ha}^{-1}\right)$} & Total & \\
\hline Baixa & 110,2 & 168,5 & 160,3 & 439,0 & \\
\hline Alta & 71,1 & 201,9 & 173,9 & 446,9 & \\
\hline Média & $84,1 \mathrm{~B}$ & $190,7 \mathrm{~A}$ & $169,3 \mathrm{~A}$ & & 21,2 \\
\hline
\end{tabular}

(1)Médias seguidas de letras distintas, minúsculas nas colunas e maiúsculas nas linhas, diferem entre si $(\mathrm{p} \leq 0,104)$ pelo teste de aleatorização. e BLF de 738,1 $\mathrm{kg} \mathrm{ha}^{-1}$ de MS, para o tratamento de baixa MF, sem suplementação.

Os baixos GMD observados, no período inicial de utilização da pastagem de aveia e azevém, podem ser conseqüência da alta quantidade de água contida nessas espécies, o que limita o consumo de MS, em virtude do enchimento do trato gastrointestinal (Restle et al., 1999).

A CA foi superior na baixa BLF, apenas no primeiro período (Tabela 2), não tendo ocorrido diferença entre as médias dos tratamentos. Isto pode ser explicado pelo índice de BLF observado nesse período, que foi superior ao pretendido para o tratamento de baixa BLF, e permitiu manter um maior número de animais reguladores, nas repetições desse tratamento, durante maior número de dias, até que fosse atingida a BLF proposta. Como as taxas de acúmulo (Tabela 3) foram semelhantes no decorrer dos períodos avaliados, as cargas mantiveramse semelhantes após a imposição dos tratamentos.

O GPV dos animais não diferiu entre tratamentos, em virtude de esse ser um produto do GMD e da CA, que não apresentaram diferenças entre as médias dos tratamentos. Os valores de GPV foram superiores aos observados por Canto et al. (1997), Restle et al. (2000), Rocha et al. (2003), Pilau et al. (2004), em solos com fertilidade e teor de nitrogênio superiores aos deste

Tabela 3. Taxas de acúmulo e produções, por período e total, de biomassas da pastagem de aveia (Avena strigosa) e azevém (Lolium multiflorum), em 2002 ${ }^{(1)}$.

\begin{tabular}{|c|c|c|c|c|c|}
\hline \multirow{2}{*}{$\begin{array}{l}\text { Quantidade } \\
\text { de BLF }\end{array}$} & \multicolumn{3}{|c|}{ Períodos de avaliação } & \multirow[t]{2}{*}{ Média } & \multirow[t]{2}{*}{$\mathrm{CV}(\%)$} \\
\hline & $5 / 7$ a $9 / 8$ & $10 / 8$ a $13 / 9$ & $14 / 9$ a $23 / 10$ & & \\
\hline & \multicolumn{5}{|c|}{ Taxa de acúmulo de biomassa $\left(\mathrm{kg} \mathrm{ha}^{-1}\right.$ por dia) } \\
\hline Baixa & 47,0 & 47,8 & 17,0 & 37,3 & \\
\hline Alta & 46,8 & 49,1 & 19,0 & 38,3 & \\
\hline \multirow[t]{2}{*}{ Média } & $46,8 \mathrm{~A}$ & $48,8 \mathrm{~A}$ & $18,3 \mathrm{~B}$ & & 34,6 \\
\hline & \multicolumn{5}{|c|}{$\begin{array}{l}\text { Taxa de acúmulo de biomassa de lâmina foliar } \\
\qquad\left(\mathrm{kg} \mathrm{ha}^{-1} \text { por dia }\right)\end{array}$} \\
\hline Baixa & 18,2 & 29,6 & $-6,3$ & 13,9 & \\
\hline Alta & 17,1 & 25,1 & $-11,9$ & 10,1 & \\
\hline \multirow[t]{2}{*}{ Média } & $17,5 \mathrm{~B}$ & $26,7 \mathrm{~A}$ & $-10,0 \mathrm{C}$ & & 54,4 \\
\hline & \multicolumn{3}{|c|}{$\begin{array}{l}\text { Produção de biomassa total } \\
\qquad\left(\mathrm{kg} \mathrm{ha}^{-1}\right)\end{array}$} & Total & \\
\hline Baixa & $1.645,0$ & $1.673,0$ & 663,0 & $4.782,4$ & \\
\hline Alta & $1.638,0$ & $1.718,5$ & 741,0 & $4.902,6$ & 25,6 \\
\hline \multirow[t]{2}{*}{ Média } & $1.638,0 \mathrm{~A}$ & $1.708,0 \mathrm{~A}$ & $616,2 \mathrm{~B}$ & & \\
\hline & \multicolumn{3}{|c|}{$\begin{array}{l}\text { Produção de biomassa de lâmina } \\
\text { foliar }\left(\mathrm{kg} \mathrm{ha}^{-1}\right)\end{array}$} & Total & \\
\hline Baixa & 637,0 & $1.036,0$ & $-245,7$ & $2.045,2$ & \\
\hline Alta & 598,5 & 878,5 & $-464,1$ & $1.639,8$ & \\
\hline Média & $612,5 \mathrm{~B}$ & $934,5 \mathrm{~A}$ & $-390,0 \mathrm{C}$ & & 48,4 \\
\hline
\end{tabular}

(1)Médias seguidas de letras diferentes, na mesma linha, diferem entre si $(\mathrm{p} \leq 0,06)$ pelo teste de aleatorização. 
experimento, mas foram inferiores aos observados por Restle et al. (1999) e Roso \& Restle (2000), em um período de utilização da pastagem superior aos 103 dias observados no presente estudo.

As taxas de acúmulo médio diário de BF foram semelhantes entre tratamentos ( $\mathrm{p}>0,13)$, no decorrer dos períodos de avaliação (Tabela 3), e foram as maiores taxas observadas até o segundo período de avaliação. A partir desse período, houve uma redução superior a $50 \%$, que pode ser atribuída ao período (39 dias) para estimativa de acúmulo de BF, aliado ao final do ciclo da pastagem, que propiciou elevadas perdas por senescência do material dentro das gaiolas de exclusão.

Com relação à taxa de acúmulo de BLF, houve um aumento do primeiro para o segundo período, na média dos tratamentos; tal tendência pode ser atribuída à aplicação de N, no início do segundo período (12/8). O N é um nutriente que determina a taxa de expansão foliar, e sua translocação para as folhas é prioritária durante o estádio vegetativo (Nabinger \& Pontes, 2001). No terceiro período, foi registrada uma taxa de senescência superior ao acúmulo de lâminas foliares, o que conferiu valores negativos a essa variável.

A produção de BF não diferiu entre tratamentos, já que essa é um produto do número de dias do período pela respectiva taxa diária de acúmulo médio, que não diferiram entre si $(p=0,925)$. A porcentagem média do período total de produção de BLF, em relação à BF, foi de $43 \%$ e $33,1 \%$, respectivamente, para a baixa e alta BLF, o que demonstra a maior produção de colmo + bainha na alta BLF.

A produção da pastagem, ao longo do período de desenvolvimento, é determinada, entre outros fatores, pelo adequado manejo da MF inicial, pelo momento do início do pastejo e pela CA utilizada (Carámbula, 1997). A BF inicial (5/7) foi de 801,4 e 805,1 $\mathrm{kg} \mathrm{ha}^{-1}$ de MS e 617,9 e $626,9 \mathrm{~kg} \mathrm{ha}^{-1}$ de BLF, para os tratamentos a serem impostos, de baixa e alta BLF, respectivamente. Esses valores de BF inicial propiciaram a manutenção de CA média dos períodos superior a $1.000 \mathrm{~kg} \mathrm{ha}^{-1} \mathrm{de} \mathrm{PV}$, além de valores GMD, na média dos períodos, que não prejudicaram a produção da pastagem.

Na Tabela 4 são apresentados os valores médios de avaliação da BF e BLF de 2003. BF e BLF, na média dos períodos, apresentaram diferença entre os tratamentos $(\mathrm{p} \leq 0,021$ e $\mathrm{p} \leq 0,167$, respectivamente para $\mathrm{BF}$ e BLF); os valores de BF foram de 763,7, 959,2 e
1.404,2 $\mathrm{kg} \mathrm{ha}^{-1}$ de MS e os de BLF foram de 352,4, 422,4 e $507 \mathrm{~kg} \mathrm{ha}^{-1}$ de MS, respectivamente, para os tratamentos de baixa, média e alta BLF.

Com relação às BLF médias dos períodos, os valores observados de 2003 foram intermediários em relação aos de 2002. Comparando-se os dois anos de avaliação, observa-se uma redução da BLF, com o aumento da BF, no tratamento de alta BLF. Em 2003, a BLF foi superior a $600 \mathrm{~kg} \mathrm{ha}^{-1}$ de MS e a BF média foi superior a $1.200 \mathrm{~kg} \mathrm{ha}^{-1} \mathrm{de} \mathrm{MS}$, enquanto no ano de 2003 os valores desse tratamento foram de 507 e $1.404,2 \mathrm{~kg} \mathrm{ha}^{-1}$ de MS, respectivamente para BLF e BF.

Na Tabela 5 estão apresentados os valores obtidos de GMD, CA e o GPV ha-1 por período de avaliação. O período de pastejo iniciou-se (17/7) com BF média de $831,8,783,5$ e $1.286 \mathrm{~kg} \mathrm{ha}^{-1}$ de MS, e $541,493,1$ e $763,3 \mathrm{~kg} \mathrm{ha}^{-1}$ de BLF, respectivamente, para os tratamentos de baixa, média e alta BLF.

A variável GMD não foi influenciada pelos valores médios de BF e de BLF observados, não tendo havido diferença significativa $(p=0,15)$ em nenhum dos períodos avaliados. Houve diferença apenas na média dos períodos ( $\mathrm{p} \leq 0,036)$; os GMD foram crescentes no decorrer dos períodos, possivelmente influenciados pela maior capacidade de ingestão de MS e pela elevação dos teores de MS da forragem.

Os GMD de 2003 foram, na média dos períodos, superiores aos observados em 2002. Ao se analisar o tratamento de baixa BLF de 2003, pode-se observar que os valores médios de BF e BLF (Tabela 4) são próximos 648 e 360,3 de MS kg ha-1 (Tabela 1), observados no ano anterior, para as variáveis citadas. Os valores de GMD desse tratamento, em 2003, reforçam os dados

Tabela 4. Biomassas de forragem e de lâminas foliares, da pastagem de aveia (Avena strigosa) e azevém (Lolium multiflorum), em $2003^{(1)}$.

\begin{tabular}{llllll}
\hline Quantidade & \multicolumn{3}{c}{ Período de avaliação } & Média & CV (\%) \\
\cline { 2 - 4 } de BLF & $17 / 7$ a 14/8 & $15 / 8$ a 12/9 & $13 / 9$ a 10/10 & & \\
\hline \multirow{5}{c}{ Biomassa de forragem } & $\left(\mathrm{kg} \mathrm{ha}^{-1}\right)$ & \\
Baixa & $574,9 \mathrm{~b}$ & $638,1 \mathrm{c}$ & $1.078,2 \mathrm{~b}$ & $763,7 \mathrm{c}$ & \\
Média & $724,2 \mathrm{ab}$ & $904,9 \mathrm{~b}$ & $1.248,7 \mathrm{~b}$ & $959,2 \mathrm{~b}$ & \\
Alta & $994,9 \mathrm{a}$ & $1.081,0 \mathrm{a}$ & $2.136,7 \mathrm{a}$ & $1.404,2 \mathrm{a}$ & \\
\hline Média & $764,6 \mathrm{~B}$ & $874,6 \mathrm{~B}$ & $1.487,9 \mathrm{~A}$ & & 7,9 \\
\hline \multicolumn{5}{c}{ Biomassa de lâminas foliares $\left(\mathrm{kg} \mathrm{ha}^{-1}\right)$} & \\
Baixa & $294,8 \mathrm{~b}$ & 393,9 & $368,5 \mathrm{~b}$ & $352,4 \mathrm{c}$ & \\
Média & $352,5 \mathrm{ab}$ & 502,1 & $412,6 \mathrm{~b}$ & $422,4 \mathrm{~b}$ & \\
Alta & $497,0 \mathrm{a}$ & 462,8 & $561,1 \mathrm{a}$ & $507,0 \mathrm{a}$ & \\
\hline Média & 381,4 & 453,0 & 447,4 & & 13,6 \\
\hline
\end{tabular}

(1)Médias seguidas de letras distintas, minúsculas nas colunas e maiúsculas na linha, diferem entre si $(\mathrm{p} \leq 0,167)$ pelo teste de aleatorização. 
de desempenho em 2002, apresentando BF e BLF próximas. Resultados de GMD superiores a $1 \mathrm{~kg}$ por animal ou próximos a esse valor, na média do período de utilização, com espécies hibernais, foram conseguidos com uso de suplementação (Santos et al., 2004) ou com animais mais velhos (Canto et al., 1997; Restle et al., 1998).

Os GPV observados na baixa e alta BLF foram próximos aos observados em 2002. Os maiores GPV foram observados na média BLF, com 626,5 $\mathrm{kg} \mathrm{ha}^{-1}$ de PV. Esse GPV foi influenciado pela maior CA média observada nos períodos de avaliação, tendo reduzido conseqüentemente, a oferta média de BF e BLF (5,74 e 2,17 kg de MS por $100 \mathrm{~kg}$ de PV).

As CA médias observadas, na baixa e alta BLF (Tabela 5), foram semelhantes às observadas em 2002 (Tabela 2). Na média BLF, foram observadas as maiores CA médias, 24\% e 31,8\% superiores às observadas,

Tabela 5. Ganho médio diário, carga animal e ganho de peso vivo por área, ofertas reais de biomassas, em pastagem de aveia (Avena strigosa) e azevém (Lolium multiflorum), em $2003^{(1)}$.

\begin{tabular}{|c|c|c|c|c|c|}
\hline \multirow{2}{*}{$\begin{array}{l}\text { Quantidade } \\
\text { de BLF }\end{array}$} & \multicolumn{3}{|c|}{ Período de avaliação } & \multirow[t]{2}{*}{ Média } & \multirow{2}{*}{$\begin{array}{l}\text { CV } \\
(\%)\end{array}$} \\
\hline & $17 / 7$ a $14 / 8$ & $15 / 8$ a $12 / 9$ & $13 / 9$ a $10 / 10$ & & \\
\hline & \multicolumn{5}{|c|}{ Ganho médio diário (kg por animal por dia) } \\
\hline Baixa & 0,893 & 1,114 & 1,137 & 1,048 & \\
\hline Média & 1,107 & 1,011 & 1,340 & 1,153 & \\
\hline Alto & 0,916 & 1,241 & 1,352 & 1,170 & \\
\hline \multirow[t]{2}{*}{ Média } & $0,972 \mathrm{~B}$ & $1,122 \mathrm{AB}$ & $1,276 \mathrm{~A}$ & & 14,0 \\
\hline & \multicolumn{5}{|c|}{ Carga animal $\left(\mathrm{kg} \mathrm{ha}^{-1}\right.$ de PV) } \\
\hline Baixa & $1.247,9$ & $950,1 \mathrm{ab}$ & $1.078,7 \mathrm{ab}$ & $1.092,2 b$ & \\
\hline Média & $1.425,4$ & $1.225,2 \mathrm{a}$ & $1.415,1 \mathrm{a}$ & $1.355,2 \mathrm{a}$ & \\
\hline Alta & $1.222,7$ & $858,6 \mathrm{~b}$ & $1.003,0 \mathrm{~b}$ & $1.028,1 \mathrm{~b}$ & \\
\hline \multirow[t]{2}{*}{ Média } & $1.298,7 \mathrm{~A}$ & $1.011,3 \mathrm{~B}$ & $1.165,6 \mathrm{~B}$ & & 14,3 \\
\hline & \multicolumn{5}{|c|}{ Oferta real de biomassa (kg de MS por $100 \mathrm{~kg}$ PV) } \\
\hline Baixa & 4,88 & $7,93 \mathrm{ab}$ & $8,46 \mathrm{ab}$ & $7,09 \mathrm{~b}$ & \\
\hline Média & 4,83 & $6,03 b$ & $6,38 b$ & $5,74 b$ & \\
\hline Alta & 8,10 & $11,94 \mathrm{a}$ & $13,32 \mathrm{a}$ & $11,12 \mathrm{a}$ & \\
\hline \multirow[t]{2}{*}{ Média } & $5,93 \mathrm{~B}$ & $8,63 \mathrm{~A}$ & $9,39 \mathrm{~A}$ & & 19,1 \\
\hline & \multicolumn{5}{|c|}{$\begin{array}{l}\text { Oferta real de biomassa de lâmina foliar } \\
\text { (kg de MS por } 100 \mathrm{~kg} \mathrm{PV})\end{array}$} \\
\hline Baixa & $2,30 \mathrm{~b}$ & 4,76 & 1,51 & $2,86 \mathrm{ab}$ & \\
\hline Média & $2,28 \mathrm{~b}$ & 3,25 & 0,97 & $2,17 b$ & \\
\hline Alta & $4,07 \mathrm{a}$ & 6,05 & 1,69 & $3,94 \mathrm{a}$ & \\
\hline \multirow[t]{2}{*}{ Média } & $2,88 \mathrm{~B}$ & $4,69 \mathrm{~A}$ & $1,39 \mathrm{C}$ & & 25,0 \\
\hline & \multicolumn{3}{|c|}{$\begin{array}{l}\text { Ganho de peso vivo por área } \\
\left(\mathrm{kg} \mathrm{ha}^{-1} \text { de PV }\right)\end{array}$} & Total & \\
\hline Baixa & 167,6 & 131,0 & $126,2 b$ & $424,8 b$ & \\
\hline Média & 265,3 & 156,3 & $204,9 a$ & $626,5 a$ & \\
\hline Alta & 191,9 & 135,1 & $142,0 \mathrm{~b}$ & $469,0 \mathrm{~b}$ & \\
\hline Média & 208,3 & 140,8 & 157,7 & & 30,0 \\
\hline
\end{tabular}

(1)Médias seguidas de letras distintas, minúsculas nas colunas e maiúsculas nas linhas, diferem entre si $(p \leq 0,104)$ pelo teste de aleatorização. respectivamente, na baixa e alta BLF. A principal justificativa foi o fato de a CA ter sido ajustada no início dos períodos, com valores projetados de taxas de acúmulo de folhas semelhantes e superiores ao ano de 2002, nos períodos, tendo resultado em lotação acima da necessária para se manter o índice proposto. Como conseqüência, foi reduzida, principalmente, a BLF do segundo para o terceiro período (Tabela 4).

Na média, as ofertas reais de BF foram de 7,09, 5,74 e 11,12 kg de MS por $100 \mathrm{~kg}$ de PV, na baixa, média e alta BLF. Os resultados obtidos nos dois anos - com ofertas reais de BF de 5,47 e 5,74 kg de MS por $100 \mathrm{~kg}$ de PV, respectivamente para a baixa BLF (2002) e média BLF (2003), com BF médias de 648 e 959,2 kg ha-1 de MS demonstraram que estão superestimados as quantidades preconizadas por Gibb \& Treacher (1976), e de MF por Mott (1984), para obtenção de um desempenho animal satisfatório.

Com relação à oferta real de BLF, observaram-se valores próximos (baixa e média BLF) e superiores (alta BLF) ao limite da capacidade ingestiva de MS desses animais, 2,75\% de PV, preconizados pelo National Research Council (1984), no primeiro período de avaliação. Mesmo as baixas ofertas reais de BLF, observadas no terceiro período, não foram limitantes ao desempenho individual e por área, com GMD e GPV, de 1,276 kg por animal e 157,7 $\mathrm{kg} \mathrm{ha}^{-1}$, respectivamente.

Na Tabela 6, estão apresentados os valores médios das taxas de acúmulo, de BF, BLF e valores de produção, por período, e total desses componentes. $\mathrm{O}$ acúmulo de BF até o dia 17/7 (entrada dos animais), foi de 1.262,7, $1.026,1$ e $1.616,5 \mathrm{~kg} \mathrm{ha}^{-1}$ de MS, e 739, 856,3 e 1.037,1 $\mathrm{kg} \mathrm{ha}^{-1}$ de MS para BLF, respectivamente, na baixa, média e alta BLF.

Os valores de acúmulo de BF observados, nos dois primeiros períodos, para baixa e média BLF, foram próximos aos observados em 2002. Embora superior em ambos os períodos na alta BLF, essa maior taxa de acúmulo não propiciou a elevação de CA, em razão de a BLF ser inferior à desejada nesses períodos.

As taxas de acúmulo de BLF demonstram produção de grande quantidade de folhas, nos dois primeiros períodos de avaliação, independentemente do ano avaliado. Essa produção foi bruscamente reduzida no terceiro período de avaliação, em virtude de a espécie de maior contribuição na área, o azevém, estar no estádio reprodutivo, tendo aumentado a produção de colmos, em conseqüência da elongação dos entrenós. 
Tabela 6. Taxas de acúmulo e produções, por período e total, de biomassas da pastagem de aveia (Avena strigosa) e azevém (Lolium multiflorum), em 2003(1).

\begin{tabular}{|c|c|c|c|c|c|}
\hline \multirow{2}{*}{$\begin{array}{l}\text { Quantidade de } \\
\text { BLF }\end{array}$} & \multicolumn{3}{|c|}{ Período de avaliação } & \multirow{2}{*}{\multicolumn{2}{|c|}{$\begin{array}{ll}\text { Média } & \mathrm{CV} \\
& (\%)\end{array}$}} \\
\hline & $17 / 7$ a $14 / 8$ & $15 / 8$ a $12 / 9$ & $13 / 9$ a $10 / 10$ & & \\
\hline & \multicolumn{5}{|c|}{ Taxa de acúmulo de biomassa $\left(\mathrm{kg} \mathrm{ha}^{-1}\right.$ por dia) } \\
\hline Baixa & $40,1 b$ & $49,9 \mathrm{ab}$ & 51,7 & $47,2 b$ & \\
\hline Média & $42,1 \mathrm{ab}$ & $41,8 \mathrm{~b}$ & 44,5 & $42,8 b$ & \\
\hline Alta & $55,3 \mathrm{a}$ & $64,7 \mathrm{a}$ & 55,7 & $58,6 \mathrm{a}$ & \\
\hline Média & 45,8 & 52,1 & 50,6 & & 11,5 \\
\hline \multicolumn{6}{|c|}{ Taxa de acúmulo de biomassa de lâmina foliar $\left(\mathrm{kg} \mathrm{ha}^{-1}\right.$ por dia $)$} \\
\hline Baixa & $18,2 \mathrm{~b}$ & $29,7 \mathrm{ab}$ & $2,9 \mathrm{a}$ & $16,9 \mathrm{~b}$ & \\
\hline Média & $19,5 \mathrm{a}$ & $21,7 b$ & $-1,3 a b$ & $13,3 \mathrm{c}$ & \\
\hline Alta & $28,1 \mathrm{a}$ & $35,5 \mathrm{a}$ & $-3,4 b$ & $20,1 \mathrm{a}$ & \\
\hline Média & $21,9 \mathrm{~B}$ & $29,0 \mathrm{~A}$ & $-0,6 \mathrm{C}$ & & 12,4 \\
\hline \multicolumn{4}{|c|}{ Produção de biomassa $\left(\mathrm{kg} \mathrm{ha}^{-1}\right)$} & Total & \\
\hline Baixa & $1.122,8 \mathrm{~b}$ & $1.447,1 \mathrm{ab}$ & $1.447,6$ & $5.280,2 b$ & \\
\hline Média & $1.178,8 \mathrm{ab}$ & $1.212,2 b$ & $1.246,0$ & $4.663,1 b$ & \\
\hline Alta & $1.548,4 \mathrm{a}$ & $1.876,3 \mathrm{a}$ & $1.559,6$ & $6.600,8 \mathrm{a}$ & \\
\hline Média & $1.282,4$ & $1.510,9$ & $1.416,8$ & & 4,1 \\
\hline \multicolumn{4}{|c|}{$\begin{array}{l}\text { Produção de biomassa de lâmina foliar } \\
\qquad\left(\mathrm{kg} \mathrm{ha}^{-1}\right)\end{array}$} & Total & \\
\hline Baixa & $509,6 \mathrm{~b}$ & $861,3 \mathrm{ab}$ & $81,2 \mathrm{a}$ & $2.191,1 b$ & \\
\hline Média & $546,0 \mathrm{a}$ & $629,3 b$ & $-36,4 a b$ & $1.995,2 b$ & \\
\hline Alta & $786,8 \mathrm{a}$ & $1.029,5 \mathrm{a}$ & $-95,2 b$ & $2.758,2 \mathrm{a}$ & \\
\hline Média & $613,2 \mathrm{~B}$ & $841,0 \mathrm{~A}$ & $-16,8 \mathrm{C}$ & & 7,6 \\
\hline
\end{tabular}

(1)Médias seguidas de letras distintas, minúsculas nas colunas e maiúsculas nas linhas, diferem entre si $(\mathrm{p} \leq 0,102)$ pelo teste de aleatorização.

\section{Conclusões}

1. As biomassas de lâminas foliares e de forragem mantidas não são fatores limitantes à produção animal.

2. A oferta real de biomassa média, a partir de $5,74 \mathrm{~kg}$ de MS por $100 \mathrm{~kg}$ de PV, permite ganhos individuais superiores a $1 \mathrm{~kg}$ por dia.

\section{Referências}

CANTO, M.W.; RESTLE, J.; QUADROS, F.L.F.; LUPATINI, G.; SOUZAA.P. Produção animal em pastagens de aveia (Avena strigosa Schreb) adubada com nitrogênio ou em mistura com ervilhaca (Vicia sativa L.). Anais da Revista da Sociedade Brasileira de Zootecnia, v.26, p.396-402, 1997.

CARÁMBUlA, M. Pasturas naturales mejoradas. 1.ed. Montevideo: Hemisferio Sur, 1997. 524p.

CORSI, M.; NASCIMENTO JUNIOR, D. Princípios de fisiologia e morfologia de plantas forrageiras aplicados ao manejo das pastagens. In: PEIXOTO, A.M.; MOURA, J.C. de; FARIA, V.P. da (Ed.). Pastagens: fundamentos da exploração racional. Piracicaba: Fealq, 1994. p.15-48.
EMBRAPA. Centro Nacional de Pesquisa de Solos (Rio de Janeiro, RJ). Sistema brasileiro de classificação de solos. Rio de Janeiro: Embrapa-CNPS, 1999. 412p.

GIBB, M.J.; TREACHER, T.T. The effect of herbage allowance on herbage intake and performance of lambs grazing perennial ryegrass and red clover swards. Journal of Agricultural Science, v.86, p.355-365, 1976.

HERINGER, I.; CARVALHO, P.C.F. Ajuste da carga animal em experimentos de pastejo: uma nova proposta. Ciência Rural, v.32, p.675-679, 2002.

HUILLIER, P.J.L.; POPPI, D.P.; FRASER, T.J. Influence of structure and composition of ryegrass and prairie grass white clover swards on the grazed horizon and diet harvested by sheep. Grass and Forage Science, v.41, p.259-267, 1986.

MANNETJE, L.'t. Measuring biomass of grassland vegetation. In: MANNETJE, L.'t.; JONES, R.M. Field and laboratory methods for grassland and animal production research. Cambridge: $\mathrm{CAB}$ International, 2000. p.151-178.

MORAES, A. Produtividade animal e dinâmica de uma pastagem de pangola (Digitaria decumbens Stent.), azevém (Lolium multiflorum Lam.) e trevo branco (Trifolium repens L.), submetida a diferentes pressões de pastejo. 1991. 200p. Tese (Doutorado) - Universidade Federal do Rio Grande do Sul, Porto Alegre.

MORENO, J.A. Clima do Rio Grande do Sul. Porto Alegre: Secretaria da Agricultura, 1961. 41p.

MOTT, G.O. Relationship of available forage and animal performance in tropical grazing systems. In: FORAGE GRASSLAND CONFERENCE, 1984, Houston. Proceedings. Lexington: American Forage and Grassland Council, 1984. p.373-377.

MOTT, G.O.; LUCAS, H.L. The design conduct and interpretation of grazing trials on cultivated and improved pastures. In: INTERNATIONAL GRASSLAND CONGRESS, 6., 1952, [Pennsylvania]. Proceedings. Pennsylvania: State College Press, 1952. p.1380-1395.

NABINGER, C.; PONTES, L.S. Morfogênese de plantas forrageiras e estrutura do pasto. In: REUNIÃO ANUAL DA SOCIEDADE BRASILEIRA DE ZOOTECNIA, 2001, Piracicaba. Anais. Piracicaba: Fealq, 2001. p.755-770.

NATIONAL RESEARCH COUNCIL. Nutrient requirement of beef cattle. $6^{\text {th }}$ ed. Washington: National Academy Press, 1984. 90p.

PILAU, A.; ROCHA, M.G.; RESTLE, J.; ESTIVALET, R.; NEVES, F.P.; QUADROS, B.P. de. Recria de novilhas de corte com diferentes níveis de suplementação energética em pastagem de aveia preta e azevém. Revista Brasileira de Zootecnia, v.33, p.2104-2113, 2004. (Suplemento, 2).

PILLAR, V.D.P. Multivariate exploratory analysis and randomization testing with MULTIV. Coenoses, v.12, p.145-148, 1997. 
RESTLE, J.; LUPATINI, G.C.; ROSO, C.; SOARES, A.B. Eficiência e desempenho de categorias de bovinos de corte em pastagem cultivada. Revista Brasileira de Zootecnia, v.27, p.397-404, 1998.

RESTLE, J.; ROSO, C.; SOARES, A.B. Produção animal e retorno econômico em misturas de gramíneas anuais de estação fria. Revista Brasileira de Zootecnia, v.28, p.235-243, 1999.

RESTLE, J.; ROSO, C.; SOARES, A.B.; LUPATINI, G.C.; ALVES FILHO, D.C.; BRONDANI, I.L. Produtividade animal e retorno econômico em pastagem de aveia preta mais azevém adubada com fontes de nitrogênio em cobertura. Revista Brasileira de Zootecnia, v.29, p.357-364, 2000.
ROCHA, M.G. da; RESTLE, J.; PILAU, A.; SANTOS, D.T. dos. Produção animal e retorno econômico da suplementação em pastagem de aveia e azevém. Ciência Rural, v.33, p.85-93, 2003.

ROSO, C.; RESTLE, J. Aveia preta, triticale e centeio em mistura com azevém. II. Produtividade animal e retorno econômico. Revista Brasileira de Zootecnia, v.29, p.85-93, 2000.

SANTOS, D.T.; ROCHA, M.G.; GENRO, T.C.M.; QUADROS, F.L.F. de; FREITAS, F.K. de; ROMAN, J.; NEVES, F.P. Suplementos energéticos para recria de novilhas de corte em pastagens anuais: análise econômica. Revista Brasileira de Zootecnia, v.33, p.2359-2368, 2004. (Suplemento, 3).

Recebido em 30 de junho de 2004 e aprovado em 13 de abril de 2005 